\title{
Residual stresses near cold-expanded hole at different stages of high- cycle fatigue by crack compliance data
}

\author{
S. I. Eleonsky, V.S. Pisarev, M.D. Zajtsev, M.Ch. Zichenkov \\ Central Aero-Hydrodynamics Institute named after Prof. N.E. Zhukousky (Ts AGI). 1 Zbukovsky Street, Zhukovsky 140180 \\ Moscow Region, Russia. \\ juzzepka@mail.ru, bttps://orcid.org/0000-0003-4345-067X \\ VSP5335@mail.ru,https://orcid.org/0000-0002-5378-609X \\ zaytcev@list.ru,zichenkov@tsagi.ru
}

\author{
M.R. Abdullin \\ Public Joint-Stock Company «Tupolev». 1 Dementiev Street, Kazan 420127, Russia. \\ maratabdullin@mail.ru
}

ABSTRACT. Experimental method for a characterization of high-cycle fatigue evolution of residual stress near cold-expanded hole is developed and implemented. The technique is based on simultaneous measurements of deformation response to narrow notch, inserted in residual stress field, on opposite specimen's faces by electronic speckle-pattern interferometry (ESPI). Two-side measurements of through notch opening displacements are performed when a single notch, emanating from cold-expanded hole edge, is inserted. The transition from in-plane displacement component to residual stress intensity factor (SIF) values follows from the relationships of modified version of the crack compliance method. The approach provides a difference in residual stress values referred to mandrel entrance and exit surface. Notches are inserted at different stages of high-cycle fatigue without applying external load. The results obtained describe fine nuances of residual stress evolution, which cannot be considered as monotonic relaxation.

KEYWORDS. High-cycle fatigue; Cold hole expansion; Residual stress intensity factor; Residual stress evolution.

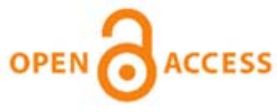

Citation: Eleonsky, S. I., Pisarev, V.S., Zajtsev, M.D., Zichenkov, M.Ch., Abdullin, M.R., Residual stresses near cold-expanded hole at different stages of high-cycle fatigue by crack compliance data, Frattura ed Integrità Strutturale, 56 (2021) 171-186.

Received: 11.03 .2021

Accepted: 18.03.2021

Published: 01.04.2021

Copyright: (C) 2021 This is an open access article under the terms of the CC-BY 4.0, which permits unrestricted use, distribution, and reproduction in any medium, provided the original author and source are credited.

\section{INTRODUCTION}

old hole expansion process is widely used to improve the fatigue life of aerospace structures [1]. The cold working of holes introduces a zone of compressive residual stresses around the hole, which, firstly, attenuates the initial crack appearance that eventually leads to an increase in damage tolerance life. Secondly, residual stress influence 
reduces the effective range of SIF thus decreasing fatigue crack growth rates [2]. Circumferential compressive residual stresses are especially beneficial at resisting fatigue when the plate with fastener holes is subjected to a tensile load. The skin of lower wing surface is the most characteristic example of tensile-dominate airplane structure.

Thus, information related to initial residual stress level as well as residual stress evolution is of considerable importance for reliable lifetime estimation. Naturally, estimation of the fatigue life without considering the residual stress evolution might lead to inaccurate results. Numerous numerical and experimental methods have been developed and implemented to solve the first from above problems [3-10].

A set of both experimental and numerical works concerns residual stress evolution [11-18]. Required data are available for restricted spectrum of loading cycle parameters. Deriving additional information, which is related to residual stress redistribution near cold-expanded holes in plane rectangular specimens under high-cycle fatigue on a base of two-side measurements, is the main goal of this paper. Plane specimens of dimensions $200 \times 70 \times 10 \mathrm{~mm}$ with centred cold-expanded hole serve as investigated objects. Specimen's thickness corresponds to the thickness of real wing panel skin. The degree of cold expansion is 0.5 per cent. Initial experimental information follows from a measurement of deformation response to narrow notch inserting in terms of notch opening displacements by ESPI. A sequence of narrow notches is used for residual stress energy release at different stages of fatigue loading with stress range $\Delta \sigma=162 \mathrm{MPa}$ and stress ratio $R=0.01$. The original point of the first non-symmetrical notch is located at the intersection of the hole boundary and the transverse symmetry axis of the specimen. Required residual SIF values are derived from the relationships developed for modified version of the crack compliance method [19].

In previous papers modified version of the crack compliance method has been implemented for residual stress characterization near cold-expanded holes [17, 18]. The objects of investigations were plane rectangular specimens measuring $180 \times 30 \times 5 \mathrm{~mm}$ with centred cold-expanded holes of diameter $2 r_{0}=4.0 \mathrm{~mm}$. Interference value was equal to $5 \%$. So high degree of cold expansion leads to circumferential residual stress of order $300 \mathrm{MPa}$ at the hole vicinity $[6,7]$. This means that a direct implementation of narrow notch inserting to quantitatively reveal residual stress level is quite difficult due to very high fringe density along the notch borders. To overcome this problem, specimens were subjected to constant tensile loading before a notch inserting $[17,18]$. This approach has two drawbacks. First, deriving SIF values, related to pure residual stress influence, needs using superposition principal. Relatively low interference level provides reason enough to obtain residual SIF values as a result of direct measurements of notch opening displacements. Second, measurements of deformation response to local material removing can be performed on only one from two external faces of the specimen. Chosen surface was mandrel entrance side.

But a significant difference in the magnitude of compressive residual stress has been established between the mandrel entry side and exit side. These data follow from both experimental and numerical analysis [10,11-14, 20,21]. The stress value has a lower value at the entry face compared to the exit face. The residual tangential stress value varies gradually, due to the material flow in axial direction caused by the mandrel, reaching maximum value at exit side. Thus, simultaneous evaluation of residual stress level on two opposite sides of the specimen is of great both applied and scientific interest.

\section{SPECIMENS AND COLD EXPANSION TECHNIQUE}

$\mathrm{F}$ atigue specimens were made from thick $1163 \mathrm{~T}$ aluminium alloy plate to the dimensions $200 \times 70 \times 10 \mathrm{~mm}$ as it is shown in Fig. 1. Russian 1163T aluminium alloy is analogous to 2024 alloy. The specimens were cut from a $1200 \times 800 \times 15 \mathrm{~mm}$ plate by the same technology so that their longitudinal axes were aligned with the plate rolling direction. Full set of RSH specimens includes 7 units. Absence of residual stresses in all specimens has been established by data of probe hole drilling and further optical interferometric measurements of deformation response to local material removing [22]. Mechanical properties such as elasticity modulus $E=74,000 \mathrm{MPa}$, yield stress $\sigma_{y}=330 \mathrm{MPa}$ and Poisson's ratio $\mu=0.33$ follow from standard tensile tests.

Each specimen contains centred open hole of nominal diameter $2 r_{0}=10.0 \mathrm{~mm}$. Pilot holes of $9.82 \mathrm{~mm}$ in diameter were drilled, followed by a $10.0 \mathrm{~mm}$ final reaming. Cold expansion process was performed by special steel tool (mandrel) of dimensions shown in Fig. 2. Narrow external mandrel ring provides a possibility of quite gradual application of loading pressure. Before carrying out cold expansion, contacting surfaces of the pin and the hole were lubricated. The forcing load has been applied by using $50 \mathrm{kN}$ capacity testing machine with a speed equal to $1 \mathrm{~mm} / \mathrm{min}$. Maximal load value reached 14 $\mathrm{kN}$. The degree of cold expansion is equal to $0.5 \%$. It is defined as relative ratio of external pin diameter to the hole diameter. A split sleeve is not introduced because of a small interference value. The same pin was used for all cold expanded holes. Specimen thickness, hole diameter and interference value correspond to real manufacturing conditions. 


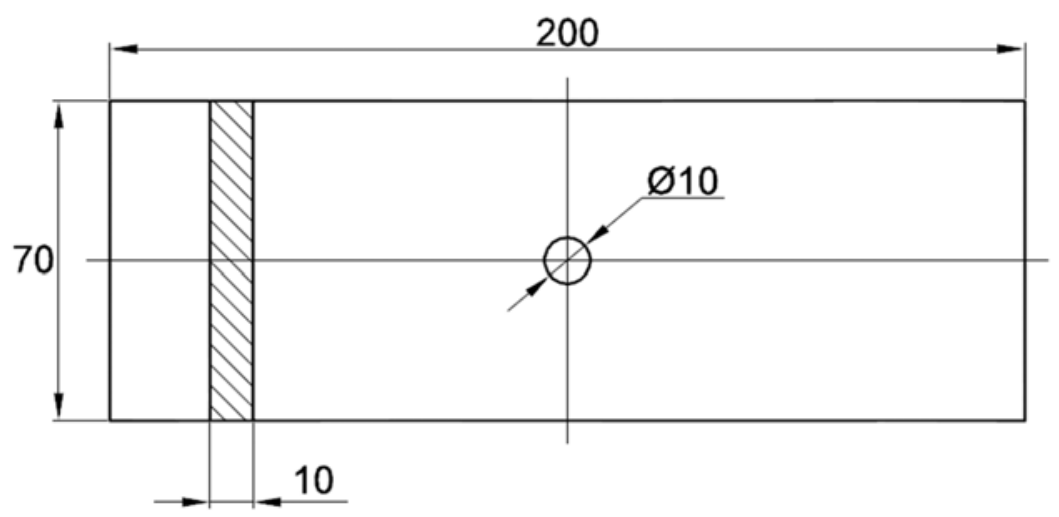

Figure 1: Drawing of specimens of RSH type.

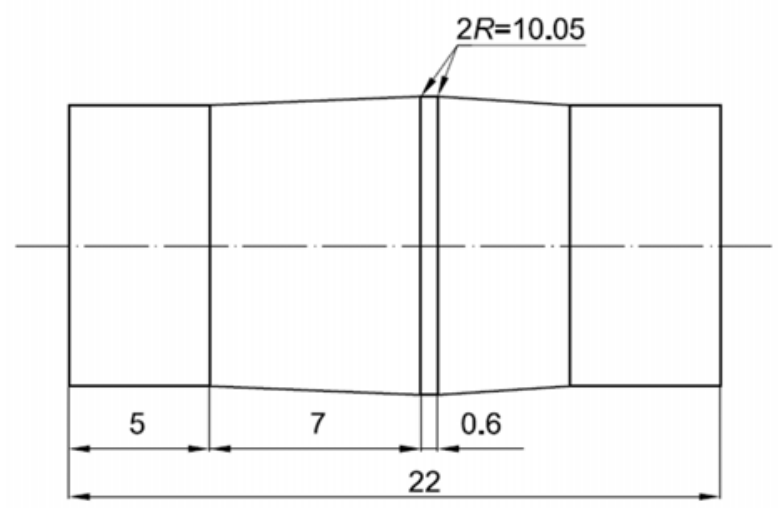

Figure 2: Cold expansion tool.

The first specimen RSH_1 is used for lifetime estimation. The second specimen RSH_2 serves for a proper choice of the first and the second notch length proceeding from fringe resolution limit. The third specimen RSH_3 gives residual stress characterization before fatigue loading. Other specimens are subjected to uniaxial pull-push sinusoidal loads with stress range $\Delta \sigma=162 \mathrm{MPa}$ and stress ratio $\mathrm{R}=0.01$. The fatigue tests were carried out with a load frequency of $3 \mathrm{~Hz}$ in MTS250 servo hydraulic testing machine. Fracture of the reference specimen occurred after $N_{\mathrm{F}}=110,000 \mathrm{cycles}$. The number of loading cycles for each investigated specimen is listed in Tab. 1.

\begin{tabular}{lcccccc}
\hline Specimen & RSH_3 & RSH_4 & RSH_5 & RSH_6 & RSH_7 & RSH_1 \\
$\begin{array}{l}\text { Number of } \\
\text { cycles, } N\end{array}$ & 0 & 20,000 & 40,000 & 60,000 & 80,000 & 110,000 \\
Lifetime, $\%$ & 0 & 18.2 & 36.4 & 54.6 & 72.7 & 100 \\
\hline
\end{tabular}

Table 1: Nomenclature of RSH specimens and fatigue loading program.

Practical realization of two-side measurements imposes heavy demands to design of experiment. Namely, a notch location as well as configuration should be carefully chosen. The point is that a specimen with gross dimensions in plane equal to $200 \times 70 \mathrm{~mm}$ can be only tested on a base of interferometer equipped with Videoscan USB-285 CCD camera. Using Videoscan USB-285 CCD camera (1200x800 pixels) with a Micro-Nikkor lens for image recording gives us an observation field of whole dimensions $28 \times 20 \mathrm{~mm}(1$ pixel $=0.0185 \mathrm{~mm})$. This means that symmetrical notches, original points of which are located at the intersection of the hole boundary and the short symmetry axis of the specimen, cannot be implemented for two-side measurements. That is why non-symmetrical notch is used for residual stress energy release as a result of local material removing.

A kinematically designed mount (KDM) serves for two-side measurements of deformation response to narrow notch inserting [23]. The upper and lower part of KDM is shown in Fig. 3. Each specimen is placed on the upper part of KDM 
so that initial notch point belonging to the hole edge coincides with the centre of both KDM parts. Assembly of the upper part of KDM with clamped specimen and the lower part of KDM are shown in Fig. 4.

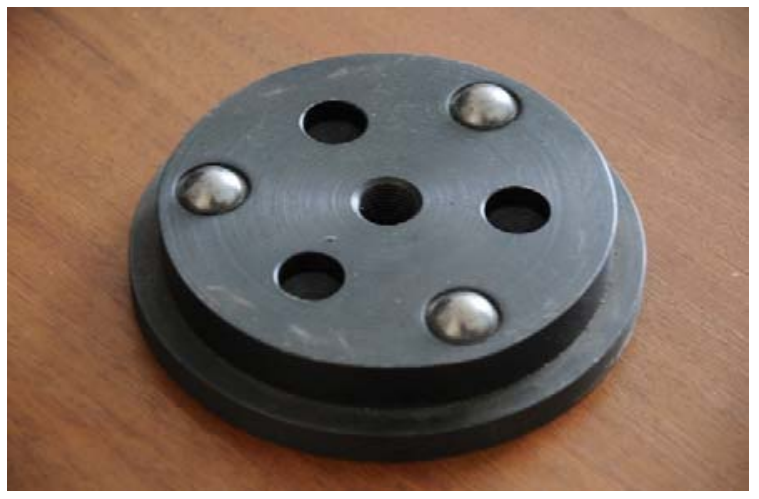

a

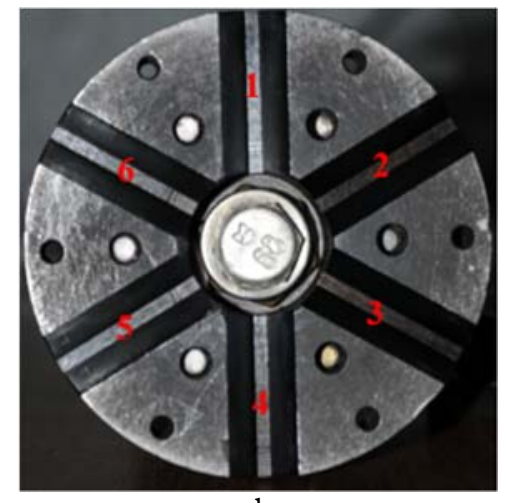

$\mathrm{b}$

Figure 3: The upper (a) and lower (b) part of kinematically designed mount.

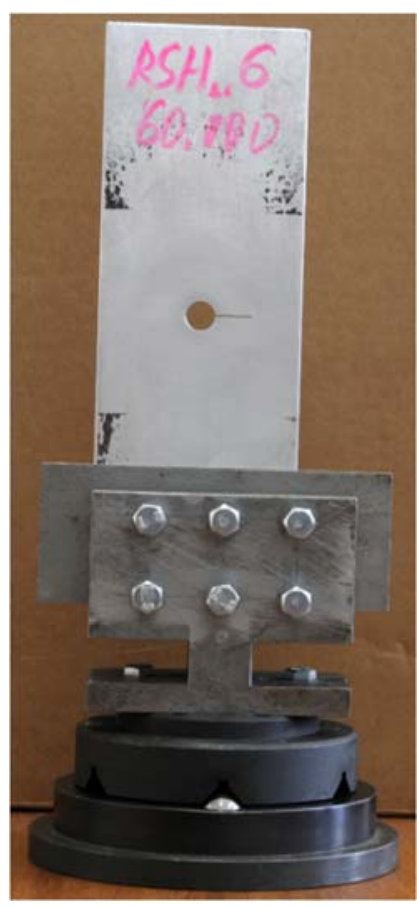

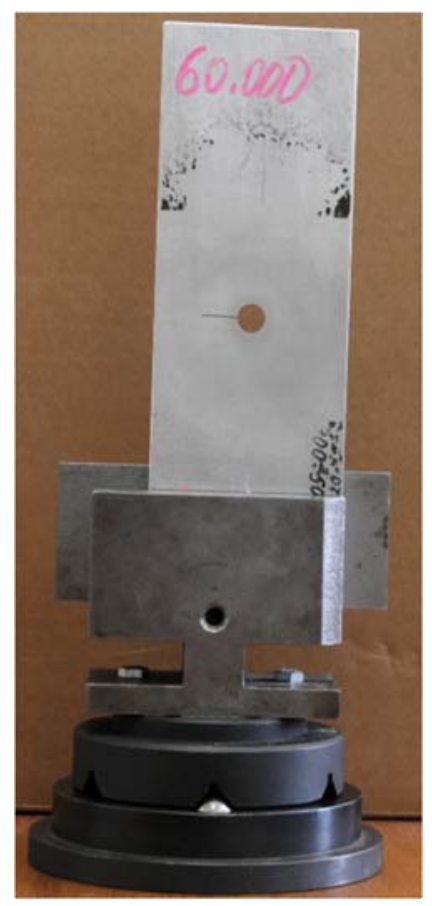

$\mathrm{b}$

Figure 4: Real view of specimen with non-symmetrical notch clamped in the upper part of kinematically designed mount: measurements on Side A (a) and Side B (b).

The main subject of present research resides in a determination of pure residual SIF values proceeding from notch opening displacement measurement. This means that only one from two in-plane displacement components, namely $v$-component, has to be derived from interference fringe pattern. Optical set-up essential for $v$-component measurement is shown in Fig.5. When projection of illumination directions onto the plane surface of the investigated object coincides with $y$-direction, interference fringe pattern is described as [19]:

$$
\nu=N^{v} \frac{\lambda}{2 \sin \Psi}
$$

where $v$ is in-plane displacement component in $y$-direction; $N^{v}= \pm 1 ; \pm 2 ; \pm 3, \ldots$ are the absolute fringe orders; $\lambda$ is the wavelength of laser illumination; $\Psi=\pi / 4$ is the angle between inclined illumination and normal observation directions. 


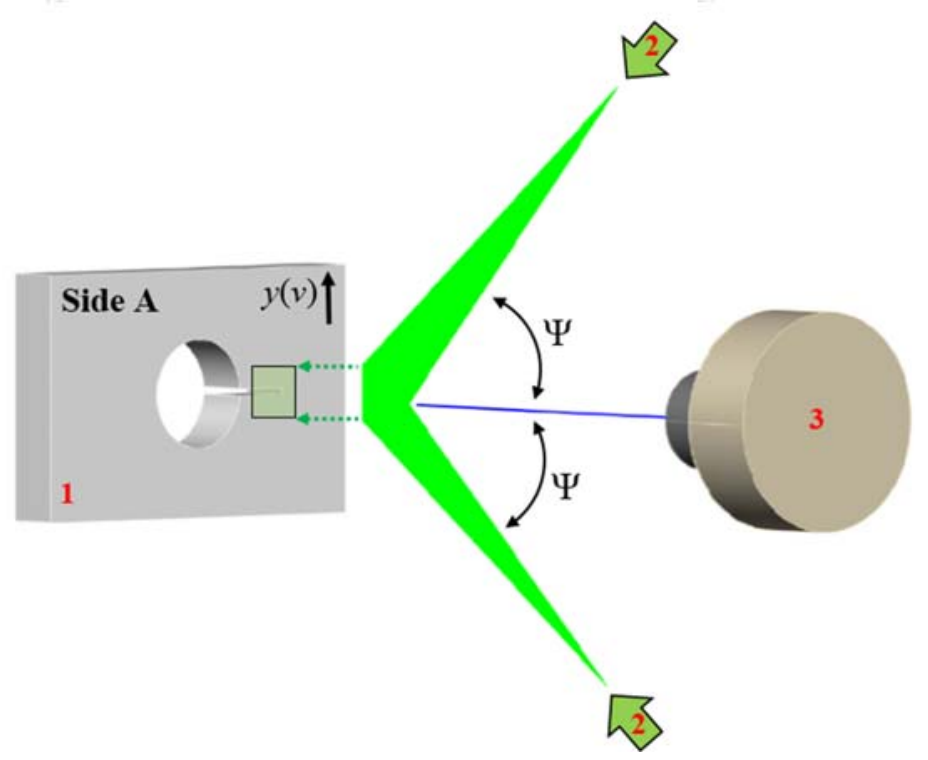

Figure 5: General scheme of obtaining interference fringe patterns for deriving in-plane displacement component $v$ by ESPI; (1) a specimen with a notch; (2) Illuminating wave of laser light; (3) a CCD camera.

A sequence of narrow notches is used for crack modelling at different stages of fatigue loading. Step-by-step procedure of notch length increasing is performed by narrow jewellery saw of width $\Delta b=0.25 \mathrm{~mm}$. The original point of the first nonsymmetrical notch is located at the intersection of the hole boundary and the short symmetry axis of the specimen. Details of experimental procedure are described in works $[17,19]$. Only short description relevant to SIF extraction from interference fringe pattern, based on notations shown in Fig. 6, follows below. The experimental procedure includes the following steps. The first exposure is made for a notch of initial length $a_{n-1}$ (see Fig. 6). Then the initial notch length is increased by a small increment $\Delta a_{n}$ so that the new total notch length becomes equal to $\Delta a_{n}=a_{n-1}+\Delta a_{n}$ and the second exposure is conducted. Interference fringe patterns required for further interpretation are visualized by numerical subtraction of two images recorded for two surface states.

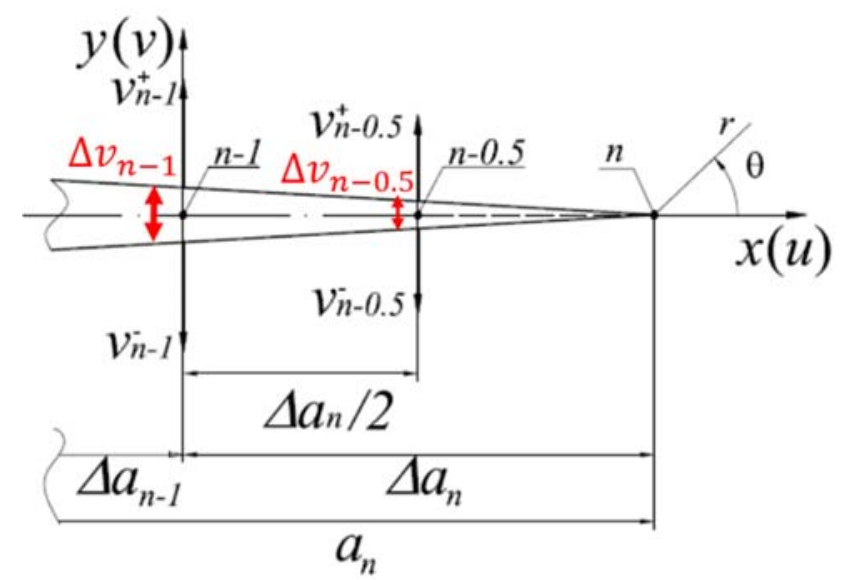

Figure 6: Polar co-ordinate system connected with the notch tip and notation used for SIF determination; $n-1$ and $n-0.5$ are the initial and final points of crack length increment $\Delta a_{n}$.

Formula for SIF determination has the following form [19]:

$$
K_{I}^{n}=\sqrt{2 \pi} A_{1}^{n}=\frac{\sqrt{2 \pi} E}{8 \sqrt{\Delta a_{n}}}\left\{2 \sqrt{2} \Delta v_{n-0.5}-\Delta v_{n-0.5}\right\}
$$


where $E$ is the elasticity modulus of the material; $\Delta a_{n}$ is the notch length increment. Two parameters in relationship (2), notch mouth opening displacement at point $n-1$ denoted as $\Delta v_{n-1}$ and notch opening displacement at point $n-0.5$ denoted as $\Delta v_{n-0.5}$, must be obtained from experimental data. These points are shown in Fig. 7.

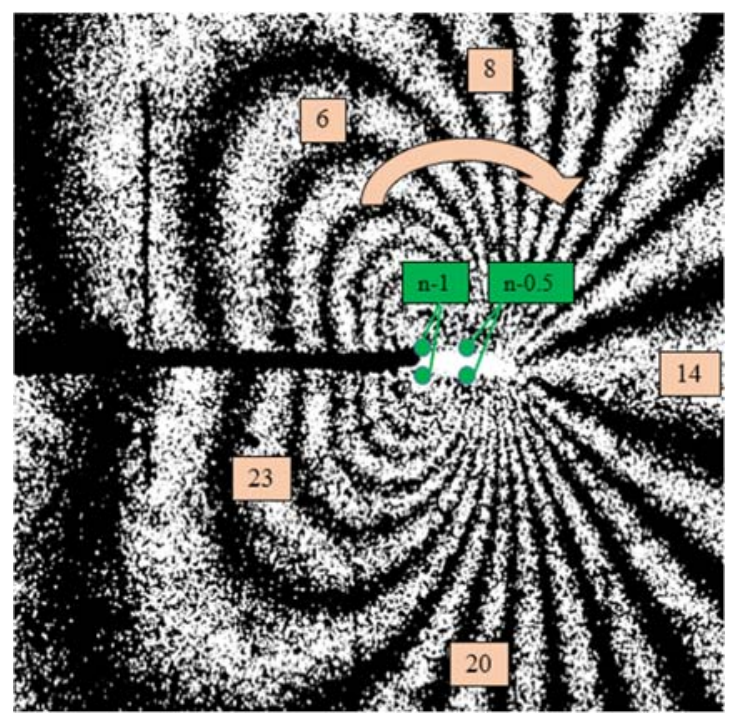

Figure 7: Typical interference fringe pattern obtained in terms of in-plane displacement component $v$ as the result of narrow notch prolongation, $\Delta N^{v}=29.0$.

Measurement procedure includes a determination of notch opening displacements in two points $n-1$ and $n-0.5$ with coordinates $\left(r=\Delta a_{n}, \theta=\pi\right)$ and $\left(r=\Delta a_{n} / 2, \theta=\pi\right)$, respectively (see Fig. 6 and 7). The point $n-1$ can be reliably identified in any interference fringe pattern of type shown in Fig. 7 as the interface between the dark and bright parts of the crack line. The point $n-0.5$ is located in the middle of the bright segment of the notch line. The value of the notch opening at points $\mathrm{n}-1$, denoted as $\Delta v_{n-1}=v_{n-1}^{+}-v_{n-1}^{-}$, can be derived in the following way. First, the absolute fringe orders in the upper and the lower notch borders, which correspond to displacement components $v_{n-1}^{+}$and $v_{n-1}^{-}$, respectively, must be calculated starting from zero order fringe. After this displacement component values $v_{n-1}^{+}$and $v_{n-1}^{-}$, are derived by formula (1):

$$
v_{n-1}^{+}=N_{n-1}^{v+} \frac{\lambda}{2 \sin \Psi}, v_{n-1}^{-}=N_{n-1}^{\nu-} \frac{\lambda}{2 \sin \Psi}
$$

$N_{n-1}^{\nu+}$ and $N_{n-1}^{\nu-}$ are the absolute fringe orders related to the upper and the lower crack borders, respectively; $\lambda$ is the wavelength of laser illumination; $\Psi=\pi / 4$ is the sensitivity angle (Fig. 5). We should keep in mind that $v_{n-1}^{+}$and $v_{n-1}^{-}$as well as $N_{n-1}^{v+}$ and $N_{n-1}^{\nu-}$ have opposite physical signs (Fig. 6). The notch mouth opening displacement (NMOD) in the point $n$ 1 follows from (3):

$$
\Delta v_{n-1}=v_{n-1}^{+}-v_{n-1}^{-}=\left(N_{n-1}^{\nu+}-N_{n-1}^{\nu-}\right) \frac{\lambda}{2 \sin \Psi}=\Delta N_{n-1}^{v} \frac{\lambda}{2 \sin \Psi},
$$

where $\Delta N_{n-1}^{v}$ is the fringe order difference referred to the point $n-1$. This value is counted over the single fringe pattern, as it is shown in Fig. 7, between two points, belonging to the upper and the lower crack borders. Interference images of large scale are used for this purpose. The value of the notch opening displacement (NOD) at the point $n-0.5$ (Fig. 6), denoted as $\Delta v_{n-0.5}=v_{n-0.5}^{+}-v_{n-0.5}^{-}$, can be determined in the same way. Thus, two experimentally measured parameters, namely NMOD 
$\Delta v_{n-1}$ (4) and NOD $\Delta v_{n-0.5}$, are available, and required SIF value $K_{I}^{n}$ for the notch of $a_{n}$ length can be determined through the use of formula (2).

\section{EXPERIMENTAL TECHNIQUE AND INITIAL INFORMATION}

he upper part of KDM includes six symmetrical $V$-shaped cuts separated by $\pi / 3$ in angular direction (Fig. 3b). Three steel balls are symmetrically arranged in the lower part of KDM divided by $2 \pi / 3$ angular distance (Fig. $3 \mathrm{a}$ ).

This design feature provides a way of performing two-side measurements. The experimental procedure developed includes following steps:

- The specimen is initially mounted so that contact between three balls and cuts numbered by 1,3 and 5 enables illumination of Side A.

- The first exposure of specimen in initial state is performed to obtain information essential for determining component $v$ on Side A;

- The specimen is turned about so that contact between three balls and cuts numbered by 2, 4 and 6 enables illumination of Side B;

- The first exposure of specimen in initial state is performed to obtain information essential for determining component $v$ on Side B;

- The specimen is removed out of the optical setup;

- Narrow notch is inserted through the specimen thickness at the surface area of interest;

- The specimen with inserted notch is replaced into interferometer system so that contact between three balls and cuts numbered by 2, 4 and 6 enables illumination of Side B;

- The second exposure of the specimen with inserted notch is performed to complete determining component $v$ on Side B;

- The specimen is turned about so that contact between three balls and cuts numbered by 1, 3 and 5 enables illumination of Side A;

- The second exposure of the specimen with inserted notch is performed to complete determining component $v$ on Side A. Above procedure has been completed for five successive notch prolongations in each from five first specimens listed in Tab. 1. Thus, $2 \times 5 \times 5=50$ interference fringe patterns, caused by local material removing, have been recorded. Interferograms obtained for the first and the second notch length increments in Specimen RSH_3 are shown in Fig. 8 and 9, respectively. Interference fringe patterns obtained for three last notch length increments in Specimen RSH_3 on Side A and Side B are presented in Fig. 10.
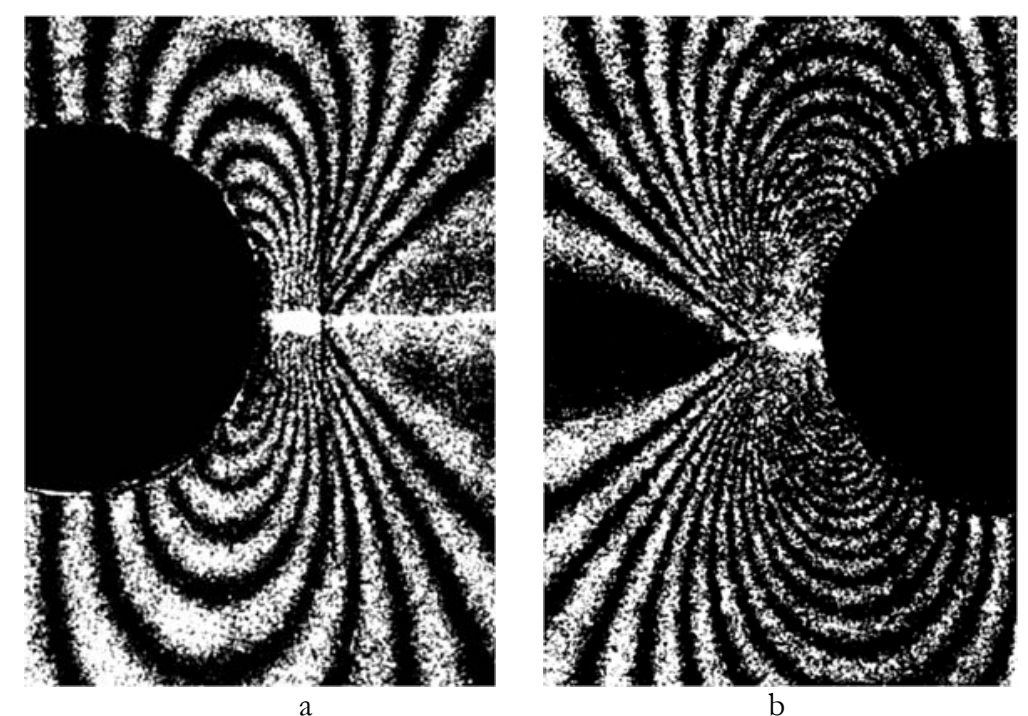

Figure 8: Specimen RSH_3. Interference fringe patterns obtained in terms of in-plane displacement component $v$ on Side A (a) and Side $\mathrm{B}$ (b) as the result of narrow notch inserting. Initial notch length $a_{0}=0$ with increment $\Delta a_{1}^{A}=1.70 \mathrm{~mm}$ and $\Delta a_{1}^{B}=1.70 \mathrm{~mm}$. 


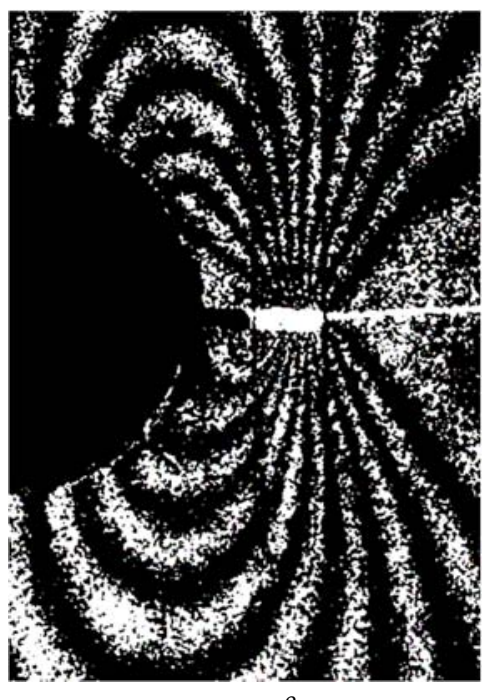

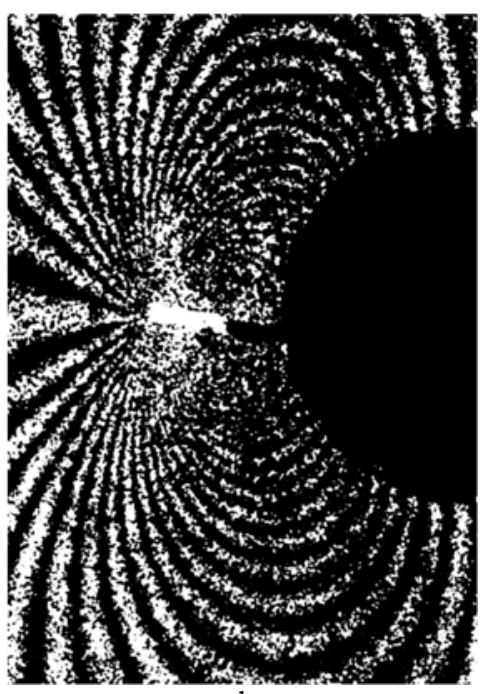

b

Figure 9: Specimen RSH_3. Interference fringe patterns obtained in terms of in-plane displacement component $v$ on Side A (a) and Side $\mathrm{B}$ (b) as the result of narrow notch inserting. Initial notch length $a_{0}^{A}=1.7 \mathrm{~mm}$ with increment $\Delta a_{2}^{A}=2.04 \mathrm{~mm}$; Initial notch length $a_{0}^{B}=1.7 \mathrm{~mm}$ with increment $\Delta a_{2}^{B}=2.15 \mathrm{~mm}$.

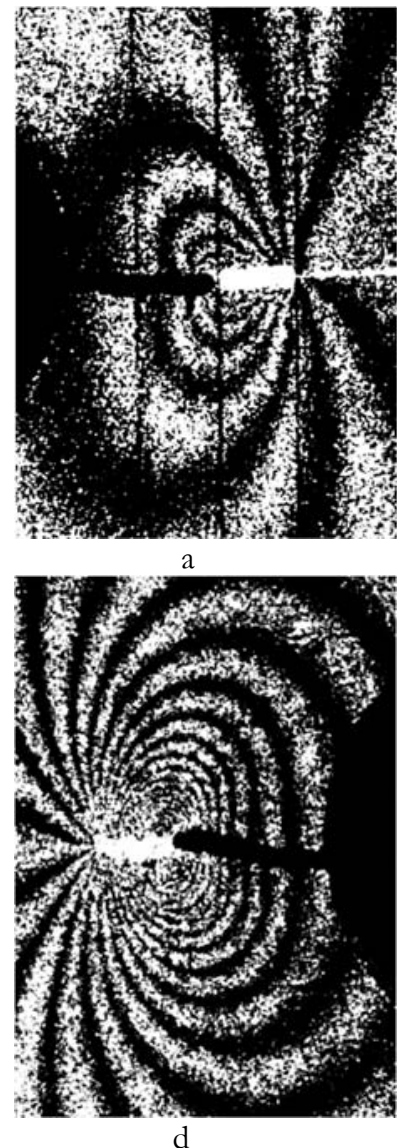

$\mathrm{d}$
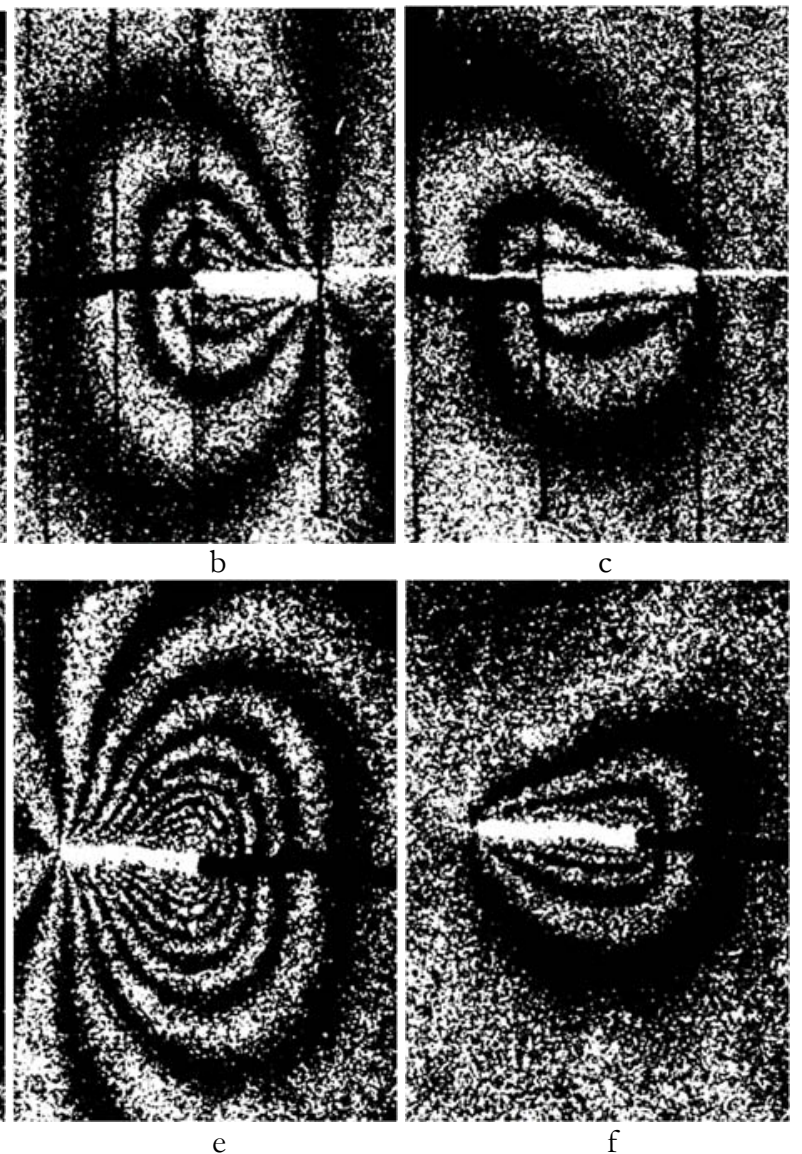

Figure 10: Specimen RSH_3. Interference fringe patterns obtained in terms of in-plane displacement component $v$ on Side A: (a)- $\Delta a_{3}^{A}$ , (b) $-\Delta a_{4}^{A}$, (c) $-\Delta a_{5}^{A}$ and Side B: (d) $-\Delta a_{3}^{B}$, (e) $-\Delta a_{4}^{B}$, (f) $-\Delta a_{5}^{B}$. 
Interferograms obtained for the first and the second notch length increments in specimen RSH_7 are shown in Fig. 11 and 12, respectively. Interference fringe patterns obtained for three last notch length increments in specimen RSH_7 on Side A and Side B are presented in Fig. 13.

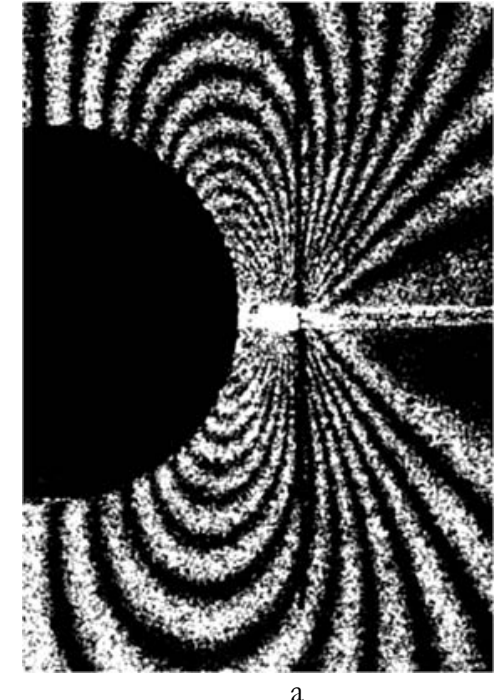

a

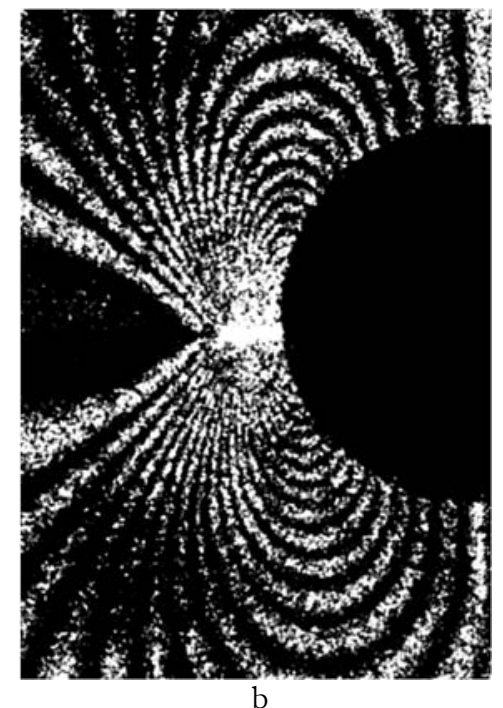

$\mathrm{b}$

Figure 11: Specimen RSH_7. Interference fringe patterns obtained in terms of in-plane displacement component $v$ on Side A (a) and Side B (b) as the result of narrow notch inserting. Initial notch length $a_{0}=0$ with increment $\Delta a_{1}^{A}=1.81 \mathrm{~mm}$ and $\Delta a_{1}^{B}=1.81 \mathrm{~mm}$.

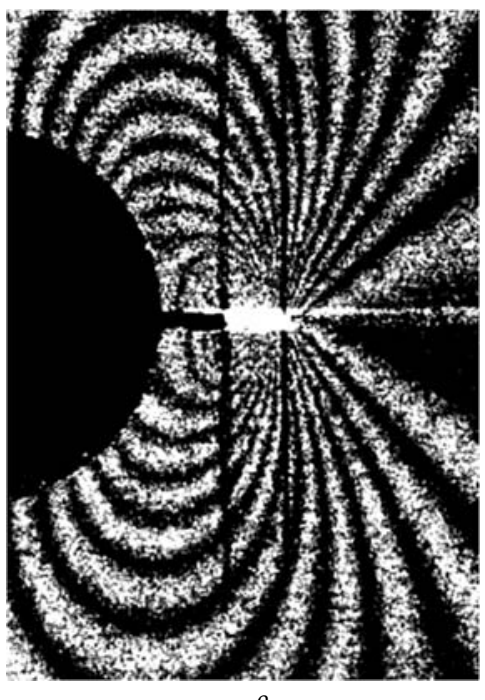

a

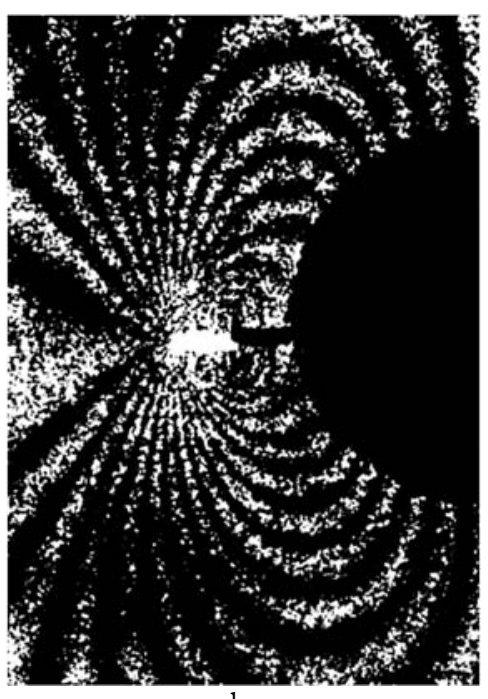

b

Figure 12: Specimen RSH_7. Interference fringe patterns obtained in terms of in-plane displacement component $v$ on Side A (a) and Side B (b) as the result of narrow notch inserting. Initial notch length $a_{0}^{A}=1.81 \mathrm{~mm}$ with increment $\Delta a_{2}^{A}=1.85 \mathrm{~mm}$; Initial notch length $a_{0}^{B}=1.81 \mathrm{~mm}$ with increment $\Delta a_{2}^{B}=1.81 \mathrm{~mm}$.

The results of interpretation of fringe patterns, obtained for Specimen RSH_3 in terms of in-plane displacement component $v$, are listed in Tab. 2. This table also includes SIF values, calculated by formula (2). The results of interpretation of fringe patterns, obtained for Specimen RSH_7 in terms of in-plane displacement component $v$, are listed in Tab. 3. This table also includes SIF values, calculated by formula (2).

The same data are also available for Specimen RSH_4, Specimen RSH_4 and Specimen RSH_6. 

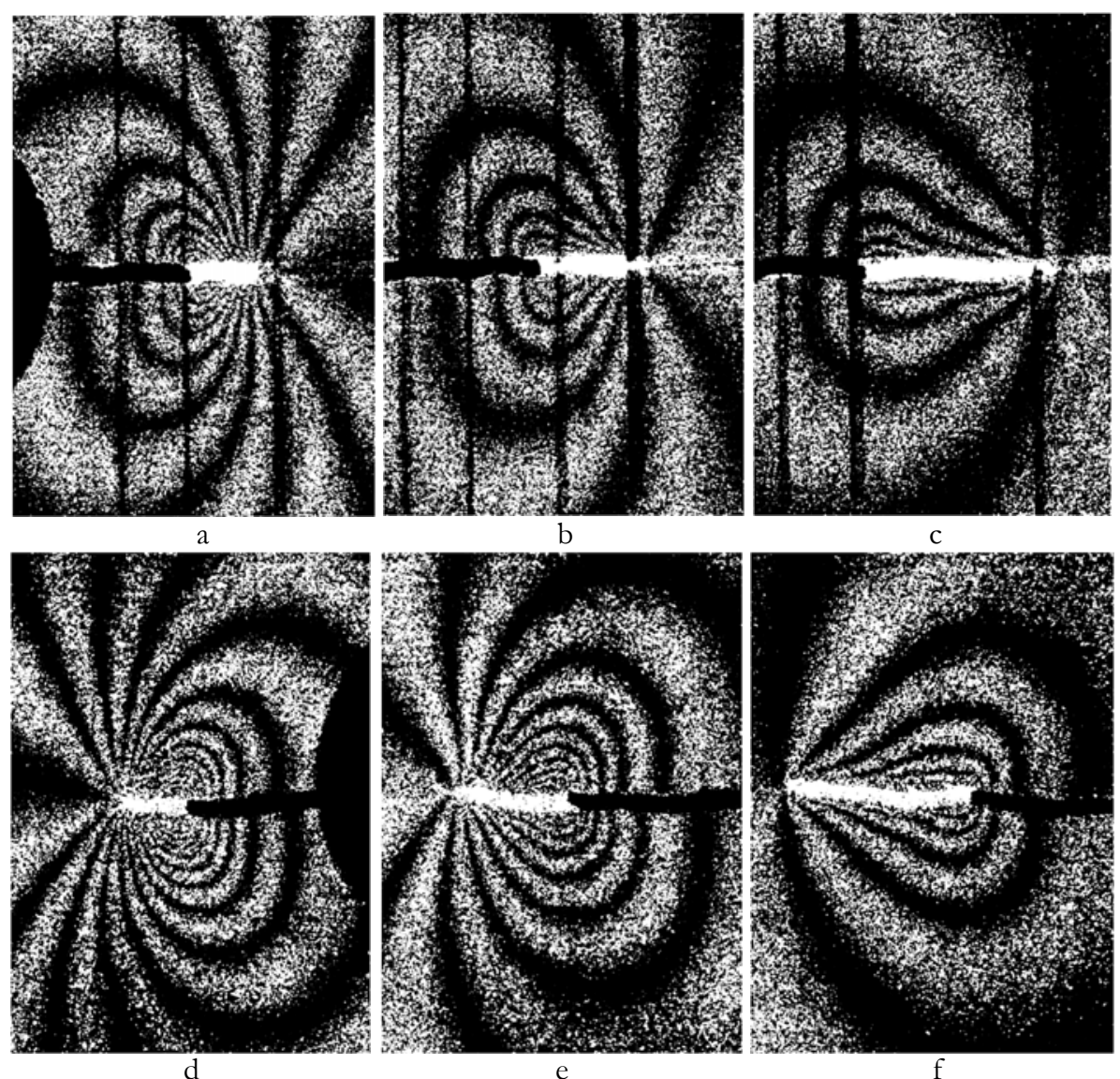

Figure 13: Specimen RSH_7. Interference fringe patterns obtained in terms of in-plane displacement component $v$ on Side A: (a)- $\Delta a_{3}^{A}$ , (b) $-\Delta a_{4}^{A}$, (c) $-\Delta a_{5}^{A}$ and Side B: (d) $-\Delta a_{3}^{B}$, (e) $-\Delta a_{4}^{B}$, (f)- $\Delta a_{5}^{B}$.

\begin{tabular}{cccccc}
\hline Notch number & 1 & \multicolumn{1}{c}{2} & 3 & 4 & 5 \\
\hline$\Delta a_{n}, \mathrm{~mm}$ & 1.70 & 2.04 & 1.96 & 2.96 & 3.74 \\
$a_{n}, \mathrm{~mm}$ & 1.70 & 3.74 & 5.7 & 8.66 & 12.4 \\
$\Delta \mathrm{N}_{n-1}^{v}$, fringes & -21.0 & -21.5 & -13.0 & -10.0 & -5.5 \\
$\Delta v_{n-1}, \mu \mathrm{m}$ & -7.98 & -8.17 & -4.94 & -3.8 & -2.09 \\
$\Delta \mathrm{N}_{n-0.5}^{v}$, fringes & -14.0 & -15.0 & -11.0 & -8.0 & -5.0 \\
$\Delta v_{n-0.5}, \mu \mathrm{m}$ & -5.32 & -5.7 & -4.18 & -3.04 & -1.9 \\
$K_{I}^{n}, \mathrm{MPa} \times \sqrt{\mathrm{m}}$ & -4.0 & -4.1 & -3.6 & -2.0 & -1.2 \\
\hline & & Side B & & & \\
\hline$\Delta a_{n}, \mathrm{~mm}$ & 1.70 & 2.15 & 1.96 & 3.33 & 3.81 \\
$a_{n}, \mathrm{~mm}$ & 1.70 & 3.85 & 5.81 & 9.14 & 12.95 \\
$\Delta \mathrm{N}_{n-1}^{v}$, fringes & -61.0 & -59.0 & -32.0 & -22.0 & -6.0 \\
$\Delta v_{n-1}, \mu \mathrm{m}$ & -23.18 & -22.42 & -12.16 & -8.36 & -2.28 \\
$\Delta \mathrm{N}_{n-0.5}^{v}$, fringes & -41.0 & -51.0 & -28.0 & -15.0 & -4.5 \\
$\Delta v_{n-0.5}, \mu \mathrm{m}$ & -15.58 & -19.38 & -10.64 & -5.7 & -1.71 \\
$K_{I}^{n}, \mathrm{MPa} \times \sqrt{\mathrm{m}}$ & -11.8 & -16.2 & -9.4 & -3.1 & -1.0 \\
\hline
\end{tabular}

Table 2: The results of fringe patterns interpretation for specimen $\mathrm{RSH}$ _3. 


\begin{tabular}{|c|c|c|c|c|c|}
\hline Notch number & 1 & 2 & 3 & 4 & 5 \\
\hline \multicolumn{6}{|c|}{ Side A } \\
\hline$\Delta a_{n}, \mathrm{~mm}$ & 1.81 & 1.85 & 1.85 & 2.81 & 5.00 \\
\hline$a_{n}, \mathrm{~mm}$ & 1.81 & 3.66 & 5.51 & 8.32 & 13.32 \\
\hline$\Delta \mathrm{N}_{n-1}^{v}$, fringes & -40.0 & -36.0 & -19.0 & -13.5 & -8.0 \\
\hline$\Delta v_{n-1}, \mu \mathrm{m}$ & -15.2 & -13.68 & -7.22 & -5.13 & -3.04 \\
\hline$\Delta N_{n-0.5}^{v}$, fringes & -31.0 & -27.0 & -13.5 & -10.0 & -6.5 \\
\hline$\Delta v_{n-0.5}, \mu \mathrm{m}$ & -11.78 & -10.26 & -5.13 & -3.8 & -2.47 \\
\hline$K_{I}^{n}, \mathrm{MPa} \times \sqrt{\mathrm{m}}$ & -9.9 & -8.3 & -3.9 & -2.5 & -1.3 \\
\hline \multicolumn{6}{|c|}{ Side B } \\
\hline$\Delta a_{n}, \mathrm{~mm}$ & 1.81 & 1.81 & 1.85 & 2.96 & 4.81 \\
\hline$a_{n}, \mathrm{~mm}$ & 1.81 & 3.62 & 5.47 & 8.43 & 13.24 \\
\hline$\Delta \mathrm{N}_{n-1}^{v}$, fringes & -50.0 & -34.0 & -25.0 & -17.5 & -10.0 \\
\hline$\Delta v_{n-1}, \mu \mathrm{m}$ & -19.0 & -12.92 & -9.5 & -6.65 & -3.8 \\
\hline$\Delta N_{n-0.5}^{v}$, fringes & -37.0 & -28.5 & -20.5 & -14.5 & -8.0 \\
\hline$\Delta v_{n-0.5}, \mu \mathrm{m}$ & -14.06 & -10.83 & -7.79 & -5.51 & -3.04 \\
\hline$K_{I}^{n}, \mathrm{MPa} \times \sqrt{\mathrm{m}}$ & -11.3 & -9.7 & -6.8 & -3.8 & -1.6 \\
\hline
\end{tabular}

Table 3: The results of fringe patterns interpretation for specimen RSH_7.

\section{RESULTS AND DISCUSSION}

$\mathrm{E}$ xperimental data of type presented in Tab. 2 and 3 offer distributions of SIF values along total crack length for specimens attributed to different loading cycles number. These dependencies are shown in Fig.14.

Dependencies, presented in Fig. 14, display considerable difference in residual SIF values, which are referred to Side A and Side B for first three notch length increments. Obtained data reliably confirm an availability of remarkable disparity between the residual stress field at the mandrel entry and exit faces. It is of crucial importance that experimental information follows from two-side measurements of deformation response to single through notch inserting, which are simultaneously performed on opposite specimen's faces. This response has a form of notch opening displacements. That is why data thus obtained is of considerable interest for refining various numerical models used for quantifying the crack tip surface displacements in the area where the corner point of the crack front intersects a free surface [24, 25].

Minimal discrepancy between residual SIF values referred to Side A and Side B is observed for Specimen RSH_7 after applying 80,000 loading cycles. A difference in residual SIF values on opposite specimen's faces is decreased starting from the third notch length. This point lies at the distance $5.5 \leq a_{3} \leq 6.2 \mathrm{~mm}$ from the hole edge. Residual SIF values for the fifth notch length increment $\Delta a_{5}$ practically coincide for all tested specimens. Experimental data reveal negative SIF values for all investigated notch length increments. This means that an influence of compressive circumferential residual stress runs to a distance equals to $5 r_{0}$ from the hole edge, as minimum, nevertheless to low interference level $(0.5 \%)$ inherent in cold expansion process.

Fig. 14 reflects residual SIF values as a function of total crack length related to different stages of high-cycle fatigue. Obtained information can be reconstructed to receive dependencies of residual SIF values for notches of fixed length against of loading cycle number. Required distributions are shown in Fig.15a and 15b for the first and the second notch length, respectively.

Plots, presented in Fig.15, indicate initial level of residual SIF $K_{I}^{1}$ and $K_{I}^{2}$ values, which are related to different distances from cold-expanded hole boundary and their evolution due to high-cycle fatigue. This evolution cannot be characterized as monotonic relaxation. Moreover, curves obtained for Side A reveal a contrary process. Naturally, initial negative SIF values are monotonically decreased when cycle number is increased. 

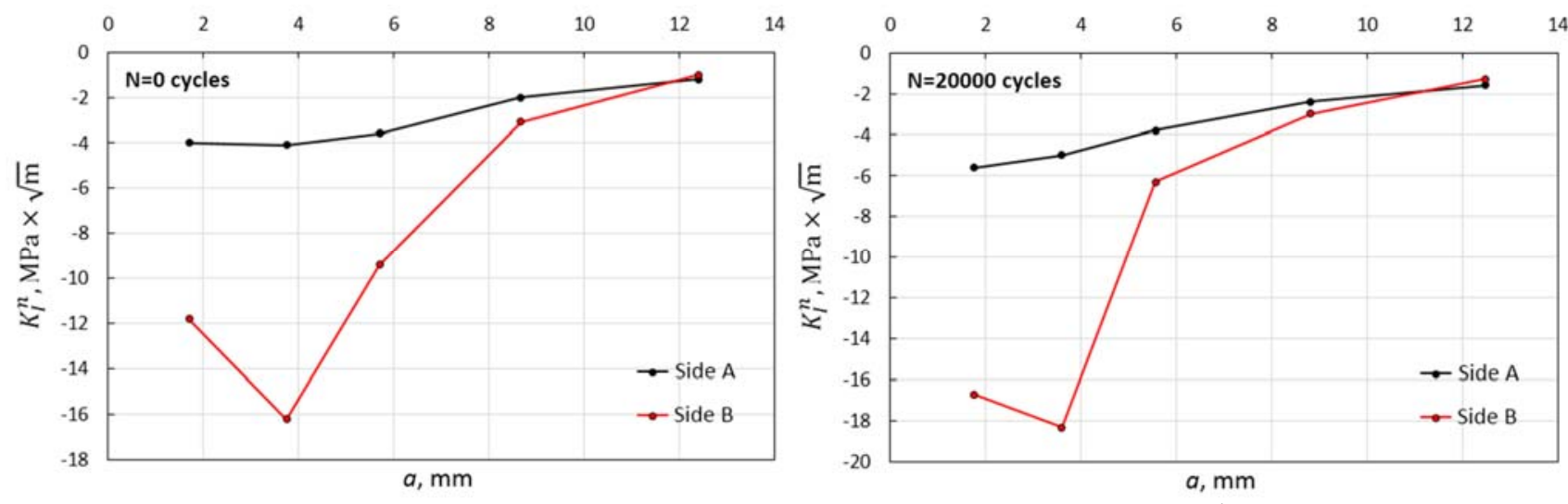

a

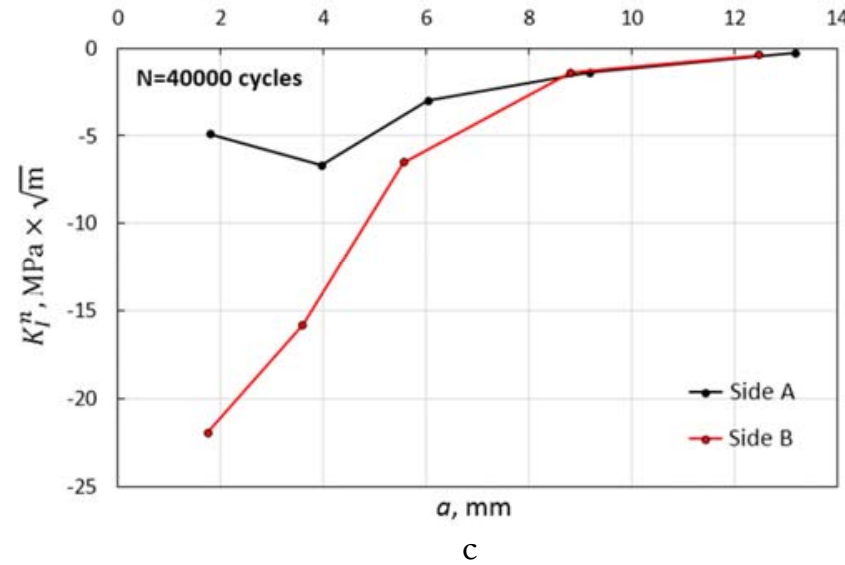

$\mathrm{b}$

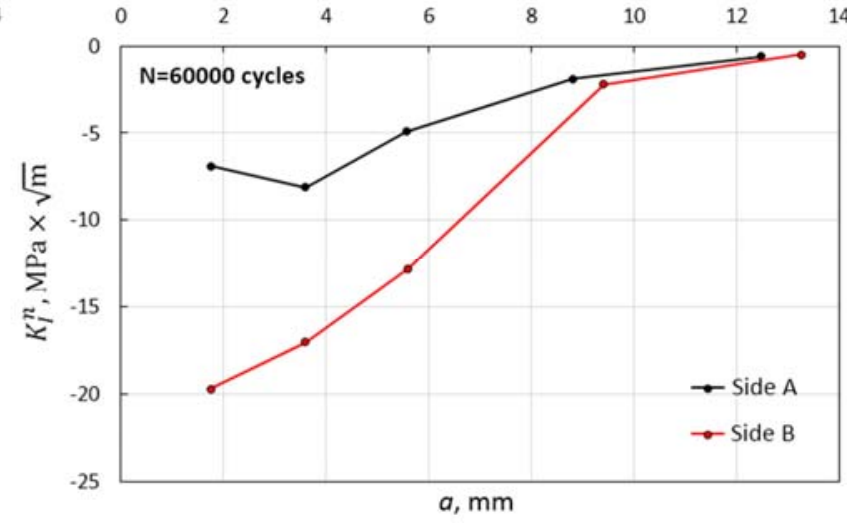

$\mathrm{d}$

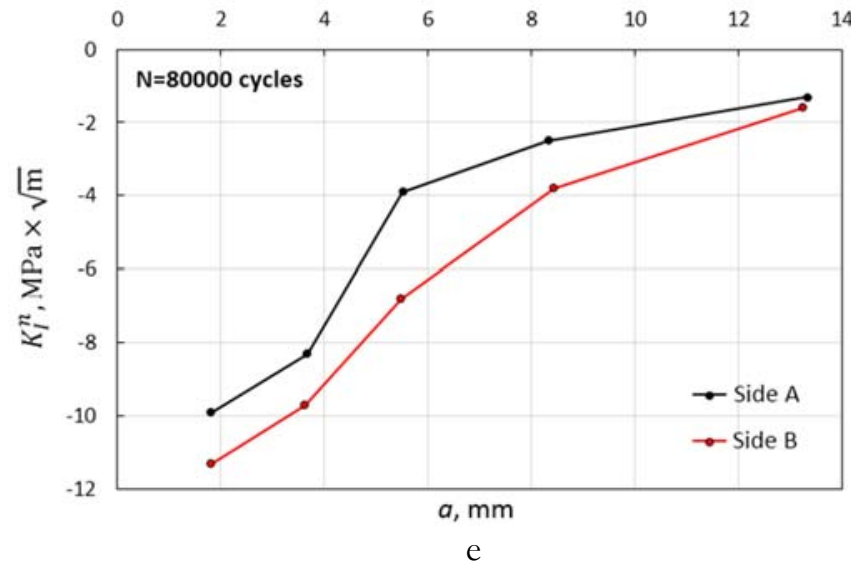

Figure 14: Residual SIF $K_{I}^{n}$ values as a function of notch length $a_{n}$ at different stages of high-cycle fatigue: $N=0$ (a); $N=20,000$ cycles (b); $N=40,000$ cycles (c); $N=60,000$ cycles (d); $N=80,000$ cycles (e).

Similar, but more complex situation, takes place for SIF redistribution on Side B (Fig. 15a). Negative $K_{I}^{1}$-values demonstrate a monotonic decrease instead of relaxation up to $N=40,000$ cycles. This stage of high-cycle fatigue corresponds to the reverse «anti-relaxation» point, after which SIF increase occurs, reaching initial value at $N=80,000$ cycles. Maximal relative increase is equal to:

$$
R_{B}^{+}=\frac{\left[K_{I}^{1}\left(R_{S} H_{-} 5\right)-K_{I}^{1}\left(R_{S} H_{-} 3\right)\right]}{K_{I}^{1}\left(R_{S} H_{-}\right)}=\frac{[-21.9+11.8]}{-21.9}=0.461 .
$$


Thus, an increase of 46 per cent in $K_{I}^{1}$-value corresponds to 36.4 per cent of lifetime. $K_{I}^{1}$-values at the initial state (specimen RSH_3) and at 72.7\% of lifetime (specimen RSH_7) coincide within 4.2 per cent (see Tab. 2 and 3). Obtained results clearly evidence that there is no «classical relaxation» of circumferential residual stress referred to Side $\mathrm{B}$.

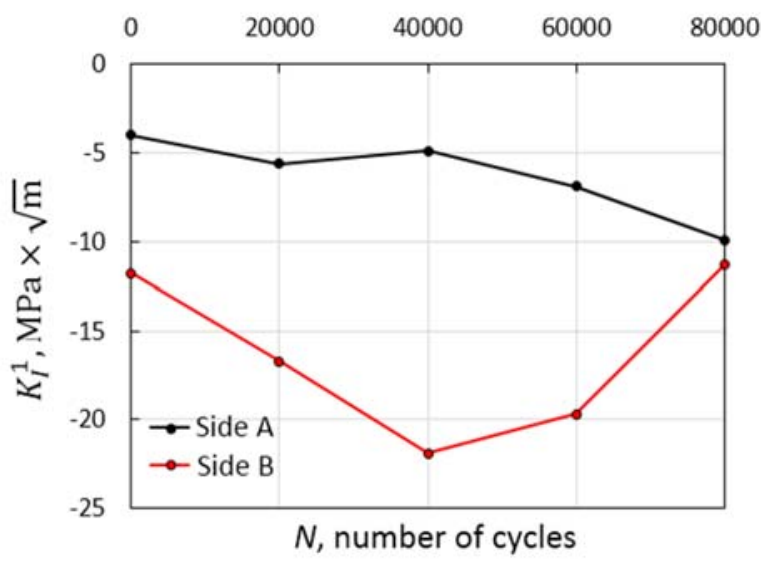

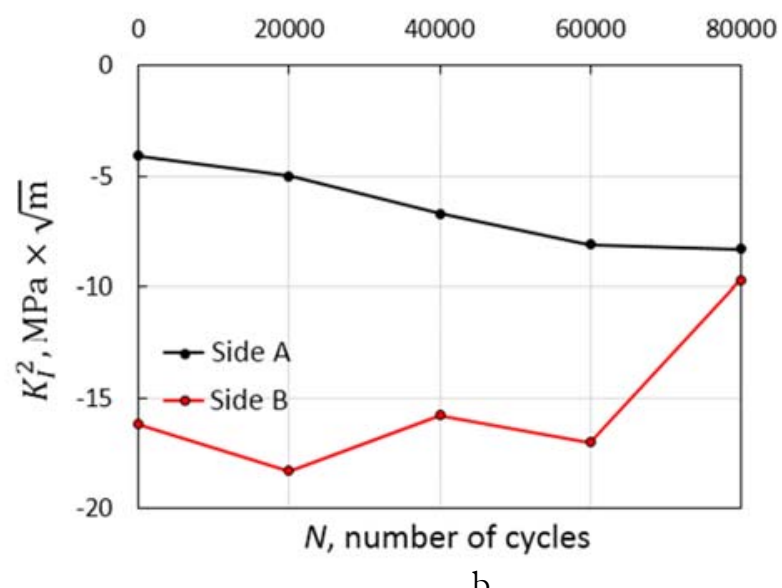

b

Figure 15: Residual SIF values as a function of loading cycle number $N$ for the first $a_{1}$ (a) and second $a_{2}$ (b) notch length increment.

The same statement is true for Side A. Maximal relative increase in $K_{I}^{1}$-value inherent in «anti-relaxation» process equals to:

$$
\mathrm{R}_{A}^{+}=\frac{\left[K_{I}^{1}\left(\mathrm{RSH}_{-} 7\right)-K_{I}^{1}\left(\mathrm{RSH}_{-} 3\right)\right]}{K_{I}^{1}\left(\mathrm{RSH}_{-} \mathrm{7}\right)}=\frac{[-9.9+4.0]}{-9.9}=0.596
$$

It should be noted that a difference in $K_{I}^{1}$-values, corresponding to $72.7 \%$ of lifetime on Side A and Side B, lies within 12.4 per cent (see Tab. 3).

Residual SIF values can be accurately converted into residual stress values based on the approach developed in a set of famous works [26-28]. But this procedure lies out of the scope of present paper, because main subject concerns residual stress evolution. That is why the analytical results presented in the handbook of Murakami [29] are involved for residual stress estimation in the cold-expanded hole vicinity. These data follow from the solution for the through non-symmetrical crack starting from the hole boundary in the infinite plane under uniform two-axes compression (section 5.2 of handbook [29]). The main feature of this approach resides in normalizing residual SIF values obtained for different specimens by $\sqrt{2 \pi a_{1}}$. This procedure serves for smoothing slight differences in experimental SIF values caused by minor deviations in the first notch length. Dependencies of principal residual stress component for the first notch against of loading cycle number are shown in Fig. 16. Obtained results should be considered as minimal possible values of circumferential residual stress component at the vicinity of cold-expanded hole edge. But evolution parameters (5) and (6) are valid for residual stress curves shown in Fig. (16).

Plots, presented in Fig. 15 and 16, confirm very interesting conclusion deals with residual stress relaxation, presented in work [30]. The author declared that «the relaxation mechanism is not clear from the physical point of view, except for the case of loads that cause macroscopic plastic deformations». Moreover, the results obtained are in direct contradiction to the opinion of authors of work [12]. They said: «cyclic loading causes these compressive residual stresses to relax, thus reducing their beneficial effect». We can see that in the case considered residual stress evolution demonstrates «anti-relax» character thus strengthening their beneficial effect.

Data concerning residual stress evolution in aluminium (7075-T73 alloy) plane specimens of 2.3 mm thickness with coldexpanded hole of $4.83 \mathrm{~mm}$ diameter are presented in work [14]: «To investigate the possible relaxation of residual stresses in cold expanded holes, specific tests were carried out. Some Split Sleeve cold expanded specimens were fatigue tested at $\Delta \sigma=160 \mathrm{MPa}, R=0.1$, up to prefixed number of cycles, in the range from $20 \%$ to $95 \%$ of the mean fatigue life. Preliminary FEM simulations ensured that the residual stress field was not altered by the application of the external fatigue load. Subsequently, round plates were machined from the fatigued specimens, to be used for Sachs' method residual stress 
measurement. The results obtained show that no relaxation was present». It is of interest that fatigue loading parameters used in present paper and work [14] practically coincide.

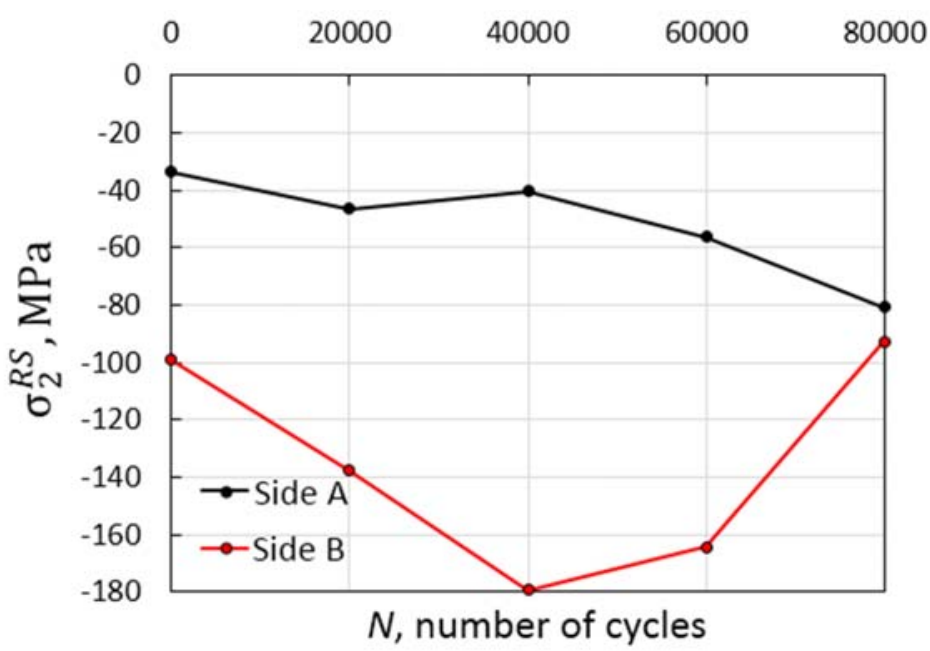

Figure 16: Values of circumferential residual stress component $\sigma_{2}^{R S}$ as a function of loading cycle number $N$ obtained for the first notch length $a_{1}$.

Revealed mechanism of residual stress redistribution is of great importance for deep understanding of the technological process used here for cold hole expansion. This process is relatively simple but leads to appropriate lifetime enhance. Evident drawback of the technology resides in low level of initial residual stress arising on Side A. But, quite unexpectedly, fatigue loading tends to an increase in negative residual stress value referred to Side A. This fact slows down fatigue crack initiation thus explaining lifetime increase inherent in cold expansion technology used.

Accurate detection of surface crack appearance was not carefully arranged. Small, but reliably visible crack (of length $a \approx$ $1.2 \mathrm{~mm}$ ), displayed on Side A after $N=95,000$ cycles. A crack of the same length was observed on Side B after 100,000 cycles.

The approach developed has two major areas of application. The first of them is connected with residual stress investigation near cold-expanded holes in thick specimens, which correspond to real thickness of aircraft components. The main advantage resides in the capability of two-side measurements thus quantifying a difference in residual SIF values referred to mandrel entrance and exit face. It is of importance that this difference considerably increases with a rise of specimen's thickness. The second field of use resides in investigations of stress range/ratio influence on residual stress evolution at the vicinity of cold-expanded holes. Note, however, that practical implementation of the experimental technique is restricted to low expansion degree. It seems that interference value must be less that one per cent.

Future developments of the approach include two directions. The first of them assumes an upgrade of interferometer optical system. The key point of this procedure resides in a decrease of interferometer sensitivity with respect to notch opening displacement. This modification will eventually lead to a gain in cold-expansion degree range, for which through notch technique might be implemented. Damage accumulation analysis related to cold-expanded hole vicinity proceeding from notch SIF evolution is the second way of further progress.

\section{CONCLUSION}

$\mathrm{N}$ ovel experimental method of residual stress characterization near cold-expanded hole is developed and implemented. The technique is based on two-side measurements of deformation response to narrow notch, which is simultaneously inserted on opposite specimen's faces. Deformation response has a form of notch opening displacements, which are measured by ESPI. The transition from in-plane displacement component to residual SIF values follows from the relationships of modified version of the crack compliance method. Two-side measurements are performed on opposite specimen's faces for a single through notch, emanating from the edge of cold-expanded hole. Thus, the approach is capable of quantifying a difference in residual stress values referred to mandrel entrance and exit surface. Notches are inserted without applying external tensile load. This means that residual SIF values are determined directly. 
Realization of developed procedure at different stages of high-cycle fatigue offers quantitative description of residual stress evolution inherent in both specimen faces. Specimens of measuring 200x70x10 mm with centred cold-expanded holes of pilot diameter $2 r_{0}=10.0 \mathrm{~mm}$ and the interference value equals to $0.5 \%$ are used to describe residual SIF evolution. Highcycle fatigue with stress range $\Delta \sigma=162 \mathrm{MPa}$ and stress ratio $R=0.01$ is considered. It is established that residual stress evolution cannot be characterised as monotonic relaxation. Initial level of negative residual stress on mandrel entrance surface reveals monotonic growth of negative values up to $72.7 \%$ of lifetime. Negative residual $K_{I}^{1}$-values, related to mandrel exit surface, demonstrate a monotonic decrease instead of relaxation up to $N=40,000$ cycles. This stage of highcycle fatigue corresponds to the reverse «anti-relaxation» point, after which SIF values increase occurs, reaching initial value at $72.7 \%$ of lifetime. A difference in $K_{I}^{1}$-values, corresponding to $72.7 \%$ of lifetime on opposite specimen faces, lies within 12.4 per cent. The approach developed has demonstrated remarkable capabilities for revealing fine nuances of residual stress evolution near cold-expanded holes. Information thus obtained is of considerable importance for development and verification of numerical methods related to residual stress analysis near cold-expanded holes.

\section{REFERENCES}

[1] Reid, L. (2014). Hole Cold Expansion - The Fatigue Mitigation Game Changer of the Past 50 Years, Advanced Materials Research, 891-892, pp. 679-684. DOI: 10.4028/www.scientific.net/AMR.891-892.679.

[2] Stefanescu, D. (2004). Measurement and prediction of fatigue crack growth from cold expanded holes, part 1: the effect of fatigue crack growth on cold expansion residual stresses, J. of Str. Analysis, 39(1), pp. 25-39.

DOI: $10.1177 / 030932470403900103$.

[3] Ball, D.L. (1995). Elastic-plastic stress analysis of cold expanded fastener holes, Fatigue and Fract. of Eng. Mat. and Struct., 18(1), pp. 47-63.

[4] Zhang, Y., Fitzpatrick, M.E., Edwards, L. (2005). Analysis of the residual stress around a cold-expanded fastener hole in a finite plate, Strain, 41(2), pp. 59-70. DOI: 10.1111/j.1475-1305.2005.00181.x.

[5] Pavier, M.J., Poussard, C.G.C., Smith D.J. (1999). Effect of residual stress around cold worked holes on fracture under superimposed mechanical load, Eng. Fract. Mechanics, 63(6), pp.751-773. DOI: 10.1016/s0013-7944(99)00050-8.

[6] Moreira, P.M.G.P., De Matos, P.F.P., Pinho, S.T., Pastrama, S.D., Camanho, P.P., De Castro, P.M.S.T. (2004). The Residual Stress Intensity Factors for Cold-Worked Cracked Holes: a Technical Note, Fatig. \& Fract. of Eng. Mat. \& Struct., (27), pp. 879-886. DOI: 10.1111/j.1460-2695.2004.00768.x.

[7] Yongshou, L., Xiaojun, S., Jun, L., Yue Zhufeng. (2010). Finite element method and experimental investigation on the residual stress fields and fatigue performance of cold expansion hole, Materials and Design, 31(3), pp. 1208-1215. DOI: $10.1016 /$ j.matdes.2009.09.031.

[8] Garcia-Granada, A.A., Pavier, M.J., Smith, D.J. (2001). A new procedure based on Sachs' boring for measuring nonaxisymmetric residual stresses: experimental application, Int. J. of Mech. Sciences, 43(12), pp. 2753-2768. DOI: 10.1016/s0020-7403(01)00071-6.

[9] Özdemir, A.T., Edwards, L. (2004). Through-thickness residual stress distribution after the cold expansion of fastener holes and its effects on fracturing, J. Eng. Mater. Technol., 126, pp. 129-135. DOI: 10.1115/1.1634278.

[10] Zuccarello, B., Di Franco, G. (2013). Numerical-experimental Method for the Analysis of Residual Stresses in Coldexpanded Holes, Exp. Mechanics; 53(4), pp. 673-686. DOI: 10.1007/s11340-012-9669-2.

[11] Ozdemir, A. T., Edwards, L. (1997). Relaxation of residual stresses at cold worked fastener holes due to fatigue loading, Fatigue Fract. Eng. Mater. Struct. 20(10), pp. 1443-51. DOI: 10.1111/j.1460-2695.1997.tb01501.x.

[12] Chakherlou T. N., Yaghoobi, A. (2010). Numerical simulation of residual stress relaxation around a cold-expanded fastener hole under longitudinal cyclic loading using different kinematic hardening models, Fatigue \& Fracture of Engineering Materials \& Structures, 33(11), pp. 740-751. DOI: 10.1111/j.1460-2695.2010.01485.x.

[13] Backman, D., Cowal, C., Patterson, E.A. (2010). Analysis of the effects of cold expansion of holes using thermoelasticity and image correlation, Fat. \& Fract. of Eng. Mat. \& Struct., 33(12), pp. 859-870. DOI: 10.1111/j.1460-2695.2010.01472.x.

[14] Boni, L., Fanteria, D., Lanciotti, A., Polese, C. (2013). Experimental and analytical assessment of fatigue and crack propagation in cold worked open hole specimens, Fatigue Fract. Engng. Mater Struct., 36(9), pp. 930-941. DOI: $10.1111 /$ ffe.12050.

[15] Keith, W.J., Ralph, W.B. (2017). Investigation of residual stress relaxation in cold expanded holes by the slitting method, Eng. Fract. Mech., 179, pp. 213-224. DOI: 10.1016/j.engfracmech.2017.05.004. 
[16] Matvienko, Y.G., Pisarev, V.S., Eleonsky, S.I. (2019). Residual stress/strain evolution due to low-cycle fatigue by removing local material volume and optical interferometric data, Fat. \& Fract. of Eng. Mat. \& Struct., 42, pp. 20612078. DOI: $10.1111 /$ ffe.13083.

[17] Matvienko, Y.G., Pisarev, V.S., Eleonsky, S.I. (2019). The effect of low-cycle fatigue on evolution of fracture mechanics parameters in residual stress field caused by cold hole expansion, Fratt. ed Int. Str., 13(47), pp. 303-320. DOI: $10.3221 /$ IGF-ESIS.47.23.

[18] Chernov, A.V., Eleonsky, S.I., Pisarev, V.S. (2021). Influence of stress ratio on residual stress evolution near coldexpanded hole due to low-cycle fatigue by crack compliance data, Fratt. ed Int. Str., 55, pp. 174-186; DOI: 10.3221/IGF-ESIS.55.13.

[19] Pisarev, V.S., Matvienko, Y.G., Eleonsky, S.I., Odintsev, I.N. (2017). Combining the crack compliance method and speckle interferometry data for determination of stress intensity factors and T-stresses, Eng. Fract. Mech., 179, pp. 348374. DOI: $10.1016 /$ j.engfracmech.2017.04.029.

[20] Pavier, M. J., Poussard, C. G. C., Smith, D. J. (1997). Finite element simulation of the cold working process for fastener holes, J. Strain Anal. Eng. Des., 32, pp. 287-300.

[21] Zhang, X., Wang, Z. (2003). Fatigue life improvement in fatigue-aged fastener holes using the cold expansion technique. Int. J. Fatigue, 25(9-11), pp. 1249-1257. DOI: 10.1016/s0142-1123(03)00152-x.

[22] Pisarev, V.S., Odintsev, I.N., Eleonsky, S.I., Apalkov, A.A. (2018). Residual stress determination by optical interferometric measurements of hole diameter increments, Optics and Lasers in Engineering, 110, pp. 437-456, DOI: $10.1016 /$ j.optlaseng.2018.06.022.

[23] Maclead, N. (1973). A kinematically designed mount for the precise location of specimen for holographic interferometry, J. of Physics E: Scien. Inst., 6, pp. 423-424.

[24] Pook, L. P., Campagnolo, A., Berto, F. (2016). Coupled fracture modes of discs and plates under anti-plane loading and a disc under in-plane shear loading, Fat. \& Fract. of Eng. Mat. \& Struct., 39(8), pp. 924-938. DOI:10.1111/ffe.12389.

[25] Pook, L. P., Berto, F., Campagnolo, A. (2016). Coupled fracture modes under anti-plane loading, Fratt. ed Int. Str., 10(37), pp. 108-113. DOI: 10.3221/IGF-ESIS.37.15.

[26] Schindler, H.-J. (1995). Determination of residual stress distributions from measured stress intensity factors, Int. J. of Fract., 74(2): R23-R30. DOI: 10.1007/bf00036266.

[27] Schindler, H.-J., Cheng, W., Finnie, I. (1997). Experimental determination of stress intensity factors due to residual stresses, Exp. Mech., 37(3), pp. 272-277. DOI: 10.1007/bf02317418.

[28] Prime, M.B. (1999). Residual stress measurement by successive extension of a slot: The crack compliance method, App. Mech. Rev, 52(2), pp. 75-96. DOI: 10.1115/1.3098926.

[29] Murakami, Y. (1987). Stress intensity factors handbook, Oxford: Pergamon.

[30] McClung, R. C. (2007). A literature survey on the stability and significance of residual stresses during fatigue, Fatigue Fract. Eng. Mater. Struct., 30(3), 173-205. DOI: 10.1111/j.1460-2695.2007.01102.x. 